\title{
Effects of Dry Fractures on Matrix Diffusion in Unsaturated Fractured Rocks
}

Yongkoo Seol, Hui Hai Liu, and Gudmundur S. Bodvarsson

Earth Sciences Division, Lawrence Berkeley National Laboratory, Berkeley, CA, USA

\begin{abstract}
Matrix diffusion has been recognized as an important mechanism affecting solute transport through unsaturated fractured rock, where a significant fraction of the fracture network remains relatively dry and inactive in conducting liquid flow. This simulation study shows that dry fractures act as strong diffusion barriers to solute transport when such fractures divide the matrix into discrete blocks. Where fracture surface roughness causes some regions of direct contact between matrix blocks separated by a dry fracture, the contacts of the matrix blocks provide conduits for liquid flow and molecular diffusion across dry fractures. Simulation results indicate that the presence of dry fractures and their discontinuities considerably affect solute transport in unsaturated fractured rocks.
\end{abstract}

\section{Introduction}

Understanding flow and transport processes in unsaturated fractured rocks is essential for evaluating the feasibility for using the unsaturated zone (UZ) of Yucca Mountain, Nevada, as a potential repository for high-level nuclear waste $[H o, 1997$; Bodvarsson et al., 1999; Robinson and Bussod, 2000]. Recent studies have indicated that matrix diffusion may be a major mechanism affecting solute transport in unsaturated fractured rocks [e.g., Bodvarsson et al., 2000; Liu et al., 2001], while the importance of matrix diffusion in saturated fractured rocks has been known for many years [Neretnieks, 
1980; Birgersson et al., 1993; Novakowski and Lapcevic, 1994; Moench, 1995; Callahan et al., 2000; Shapiro, 2001]. Owing to the orders-of-magnitude slower flow velocity in matrix blocks than in fractures, the migration of radionuclide from fractures to matrix can significantly retard radionuclide transport.

Unsaturated flow in fractured rocks is complicated, because of complex fracturematrix interaction, subsurface heterogeneity, and nonlinearity of unsaturated flow in fracture networks [Rasmussen, 1991; Glass et al., 1996; Pruess, 1999]. A number of researchers [e.g., Liu et al., 1998; Pruess et al., 1999] have suggested that in unsaturated fractured rocks, preferential flow occurs at both a single-fracture scale and a connected fracture-network scale, with only a portion of fractures conducting liquid water in the UZ. A significant portion of fractures within fracture networks remains inactive and relatively dry (Figure 1).

The impact of these dry fractures on solute transport in the UZ has not been previously investigated. These dry fractures could limit flow and transport by serving as barriers, particularly for matrix diffusion between matrix blocks separated by these fractures. Therefore, it is important to examine the impact of dry fractures on matrix diffusion in the UZ. Furthermore, fractures can be discontinuous where fracture surface roughness causes direct contacts between matrix blocks (Figure 2). As a result, two adjacent matrix blocks may not be completely separated by dry fractures, with the resulting direct matrix-matrix connections potentially providing pathways for liquid flow as well as solute transport [Wang and Narashimhan, 1993]. 
This study examines the effect of dry fractures on matrix diffusion over a range of molecular diffusion coefficients and for various degrees of matrix contacts (or connections) within dry fractures.

\section{Numerical Experiments}

Numerical experiments were conducted using the simple two-dimensional parallel fracture-matrix system. The fracture and matrix hydraulic properties listed on Table 1 are the same as those for a potential repository layer in Yucca Mountain, which is a crystalpoor middle nonlithophysal unit in the Topopah Spring welded hydrogeological unit [Ahler and Liu, 2000].

The fracture-matrix system $(200 \mathrm{~m}$ high $\times 4.5 \mathrm{~m}$ wide $\times 1 \mathrm{~m}$ thick $)$ consists of 15 matrix blocks, with a width of $0.2998 \mathrm{~m}$, separated by 14 vertical fractures with an aperture of $0.0002 \mathrm{~m}$. The fracture spacing was chosen to be close to average fracture spacing in the repository layer [Nieder-Westermann, 2000]. Two half-fractures were placed at both side-ends of the system. Liquid injection was applied at the top of the fracture on the left side and all other fractures were considered inactive or dry fractures. This results in active fracture spacing of $9 \mathrm{~m}$ due to symmetry, which is within the range of previous researches [Pruess 1997; Pruess et al., 1999]. Active fractures are defined as those that conduct liquid water [Liu et al., 1998], corresponding the half fracture where liquid transport occurs. The first two matrix blocks close to the active fracture were further refined horizontally into 5 sub-matrix blocks to accurately model the relatively steep saturation and concentration gradients near the active fracture. All matrix and fracture blocks were vertically divided into 20 elements, each $10 \mathrm{~m}$ in height. The 
fracture-matrix system employed in this study is rather simple, but should be able to capture the effects of dry fractures on solute transports in the UZ.

To consider the asperity of matrix blocks (matrix-matrix direct contacts) across dry fractures, interface areas between matrix and dry fractures were reduced to $80 \%$ (or $90 \%)$ of the initial fracture-matrix interface area $\left(10 \mathrm{~m}^{2}\right)$, and subsequently the two matrix blocks bordering a dry fracture were directly connected with $20 \%$ (or 10\%) of the initial fracture-matrix interface area. However, fracture-matrix interface areas for the two half-fractures at the two sides of the model domain were kept unchanged. In this way, the direct matrix-matrix contacts were uniformly distributed over the entire system except on the two half-fractures. In addition, a fracture-matrix interface area reduction factor was set equal to the water saturation in fractures. It is based on the hypothesis that liquid water in an unsaturated fracture occurs as saturated segments covering a portion of the fracture-matrix interface area [Wang and Narashimhan, 1993] and subsequently the reduction of fracture-matrix interaction is caused by low water saturation in the fractures. A detailed discussion of fracture-matrix interface area reduction can be found in Liu et al. [1998].

The top boundary of the model domain is defined to be a no-flow boundary except at the active fracture. The sides of the model domain were assigned to be impermeable symmetry boundaries while a free drainage condition was prescribed at the bottom. Constitutive relations for both fractures and the matrix were assumed to follow the van Genuchten [1980] and Mualem [1976] model (Table 1).

Simulations were performed for five cases, which are identified by the presence of dry fractures and a varying degree of direct matrix-matrix contact across dry fractures. 
The five cases include a fracture-matrix system with dry fractures and no direct matrixmatrix connection; three systems with dry fractures and direct matrix-matrix connection with various matrix-matrix interface area equal to $1 \%, 10 \%$, and $20 \%$ of the fracturematrix interface area, respectively; and finally a system without dry fractures between the two half fractures at the two sides of the model domain. For the last case, all the fractures between the two half fractures were treated as part of the rock matrix. For each case, four different molecular diffusion coefficients $\left(\mathrm{D}_{0}\right)$ were used to simulate the breakthrough curves of (1) a non-diffusive conservative tracer $\left(D_{0}=0.0 \mathrm{~m}^{2} / \mathrm{s}\right)$, (2) a low-diffusive conservative tracer $\left(\mathrm{D}_{0}=3.20 \times 10^{-11} \mathrm{~m}^{2} / \mathrm{s}\right),(3)$ a radionuclide $\left(\right.$ e.g., $\left.{ }^{99} \mathrm{Tc}\right)$ with a molecular diffusion coefficient of $4.55 \times 10^{-10}\left(\mathrm{~m}^{2} / \mathrm{s}\right)$, and (4) an typical environmental tracer (e.g., $\mathrm{Cl}^{-}$) with a high molecular diffusion coefficient of $2.00 \times 10^{-9}\left(\mathrm{~m}^{2} / \mathrm{s}\right)$ [Moridis and $\mathrm{Hu}$, 2000]. The range of diffusion coefficients would include those of most radionuclides, including daughter elements and environmental tracers.

Liquid water was injected isothermally from the top of the active fracture, corresponding to a time-invariant average percolation flux of $5 \mathrm{~mm} / \mathrm{year}$ over the entire system, which is consistent with the average net infiltration rate for the Yucca Mountain site [Flint et al., 1997]. After a steady-state water flow field was obtained, a pulse of tracer was added along with the applied water at the top of the active fracture. The concentration of the radioactive solutes or conservative tracer added was too low to have significant effect on the fluid properties. Initial tracer concentrations were set at zero throughout the domain. Breakthrough curves of the tracer were observed at the bottom of the model domain, represented by the ratio of bottom cumulative tracer flux $(\mathrm{kg})$ to initial tracer mass placed into the source element. The T2R3D code [Wu et al., 1996] was used 
for simulating solute transport in this study. For simplicity the radioactive decay and dispersion was inactivated in this study.

\section{Results and Discussion}

Figure 4a compares breakthrough curves for various molecular diffusion coefficients in the fracture-matrix system without dry fractures intersecting matrix blocks. With relatively high molecular diffusion coefficients $\left(\mathrm{D}_{0} \geq 4.55 \times 10^{-10} \mathrm{~m}^{2} / \mathrm{s}\right)$, median fronts $\left(\mathrm{C} / \mathrm{C}_{0}=0.5\right)$ of solute transport reached the bottom of the fracture-matrix system in about 7,500 years, which is significantly later than that for a solute with smaller

molecular diffusion (e.g., $3.20 \times 10^{-11} \mathrm{~m}^{2} / \mathrm{s}$, Figure 4). This result supports the hypothesis that for a unsaturated hydrologic system with a flow regime dominated by fracture flow, matrix diffusion can significantly retard solute transports [Bodvarsson et al., 2000].

Breakthrough curves for the fracture-matrix system with dry fractures are shown in Figure 4b. Unlike the results from the system without dry fractures, relatively little retardation of solute transport resulted from matrix diffusion, because dry fractures prevent the solutes from farther diffusing into matrix blocks. This interpretation is supported by the horizontal distribution of water saturation in the fracture-matrix system (Figure 5) calculated for the middle of the fracture-matrix system (height $=100 \mathrm{~m}$ ). Sharp decreases in water saturation occurred at the locations of two fractures close to the active fracture. A low uniform matrix saturation distribution was observed beyond the two matrix blocks closest to the active fracture. Liquid percolation through the active fracture causes water saturation in the first matrix block to increase to $99 \%$. This is followed by increased saturation in the first dry fracture, which further results in 
increased water saturation in the second matrix block (Figure 5). This indicates that dry fractures can act as capillary barriers for liquid flow when matrix blocks are completely separated, which is consistent with the discussion of Pruess [1999].

Most fractures would have some discontinuity and surface roughness, which creates heterogeneity in fracture aperture distributions. With those irregularities in dry fractures, continuity of matrix blocks over dry fractures exists in fractured rocks (Figure 2). To consider this, we assumed that within a dry fracture, a certain degree of horizontal matrix continuation occurred, while the vertical flow path within the fracture remained unchanged. The simulated matrix saturation distribution is also shown in Figure 5 for the case of $10 \%$ matrix-matrix direct connection. This distribution was quite uniform along the horizontal direction, indicating that under steady-state flow conditions, the barrier effect of dry fractures is not very effective for liquid flow when matrix blocks are partially connected across dry fractures. Similar results were observed for the $1 \%$ and $20 \%$ horizontal matrix-matrix connections.

Table 2 summarizes the maximum horizontal liquid velocity and Peclet numbers defined as:

$$
\mathrm{P}=v \mathrm{~d} / \mathrm{D}_{\mathrm{e}}
$$

where $v$ is the horizontal flow velocity, $\mathrm{d}$ is the characteristic length defined as the width of a matrix block $(0.2998 \mathrm{~m})$, and $\mathrm{D}_{\mathrm{e}}$ is the effective diffusion coefficient $\left(\mathrm{D}_{\mathrm{e}}=\tau \cdot \mathrm{D}_{0}\right.$, where $\tau$ is tortuosity). Maximum horizontal velocities were observed at the interface between the active fracture and the first matrix block. The presence of direct matrixmatrix connections within dry fractures increases horizontal liquid velocities in the system. The small Peclet numbers (Table 2) support the argument of Bodvarsson et al. 
[2000] that solute transport in the matrix is dominated by diffusion, and mechanical dispersion can be ignored.

Figure 6a shows breakthrough curves for a low molecular diffusion coefficient of $3.20 \mathrm{E}-11 \mathrm{~m}^{2} / \mathrm{s}$ and for different degrees of horizontal matrix continuation across dry fractures. The extent of horizontal matrix-matrix connection has little effect on the curves before 500 years, because matrix diffusion occurs in the first matrix block adjacent to the active fracture only during that time period. The differences among breakthrough curves after 500 years results from diffusion into other matrix blocks beyond the first dry fracture. As the degree of connection increases, more solute diffuses into the matrix blocks.

Breakthrough curves for a typical radionuclide $\left(\mathrm{D}_{0}=4.55 \times 10^{-10} \mathrm{~m}^{2} / \mathrm{s}\right)$ and an environmental tracer $\left(D_{0}=2.005 \times 10^{-9} \mathrm{~m}^{2} / \mathrm{s}\right)$ are shown in Figure $6 \mathrm{~b}$ and $6 \mathrm{c}$, respectively. Compared with Figure 6a, higher degrees of horizontal matrix-matrix continuation resulted in delayed arrivals of solute fronts and larger relative concentrations at the late times due to stronger back diffusion. With the larger diffusion coefficient, a larger amount of solute can be transported to other matrix blocks beyond the block adjacent to the active fracture by diffusion through direct matrix-matrix connections. As a result, the impact of dry fractures as diffusion barriers becomes more significant for larger molecular diffusion coefficients, as indicated by comparing results given in Figures 6a and $6 \mathrm{~b}$. However, a comparison between Figures $6 \mathrm{~b}$ and $6 \mathrm{c}$ indicates that for the molecular diffusion coefficients larger than $4.55 \times 10^{-10} \mathrm{~m}^{2} / \mathrm{s}$, the breakthrough curves seem to become less sensitive to the change in degree of matrix-matrix direct connections for relatively large degrees of matrix-matrix connections (e.g., 10\% and larger). This is 
because a 10\% connection, in this case, already provides sufficient diffusion paths; a further increase in the matrix-matrix connection does not significantly increase diffusive transport through the connection. Simulation results also indicate that the simulated breakthrough curves are very sensitive to the change in degree of matrix-matrix direct connection for relatively small degrees of such connections (e.g., less than 10\%) because even a very small matrix-matrix connection $(\approx 1 \%)$ may be able to transfer a considerable amount of solutes through diffusion.

Since a typical degree of matrix-matrix connection is about $10 \%$ according to Wang and Narashimhan [1993], comparisons between results obtained with and without considering dry fractures suggest that the transport of typical radionuclides (e.g., Tc) is most significantly affected by the existence of dry fractures (Figure 6b). Figure 7 shows distributions of the tracer with $\mathrm{D}_{0}=4.55 \mathrm{E}-10 \mathrm{~m}^{2} / \mathrm{s}$ at the simulation time of 3,000 years. With a pulse injection of tracer at the active fracture, a major portion of tracer is flushed out through the active fracture, and a plume of diffusing tracer occurs in the matrix. The distribution of the diffusing tracer is controlled by water saturation and the dominant direction of diffusion. When the matrix blocks are not connected directly, solute transport is dominated by vertical advective movement (Figure 7a). But with only $1 \%$ matrix-matrix connection, solute can diffuse farther into the matrix block (Figure 7b), and solute transport has a significant contribution from horizontal diffusive transport with direct matrix connections (Figure $7 \mathrm{c}$ and $7 \mathrm{~d}$ ). Therefore, the matrix connection can change the flow regime responsible for solute transport and can retard the transport of solutes via horizontal diffusion. The results of this study imply that models that do not 
consider the effects of dry fractures may underestimate radionuclide travel times through the unsaturated zone of Yucca Mountain.

\section{Conclusions}

Through numerical simulations, we have examined the impacts of dry fractures and their discontinuous separation of matrix blocks on matrix diffusion of radionuclides and environmental tracers. Our simulation results, consistent with previous studies, indicate that matrix diffusion can significantly retard solute transport even when dominant water flow occurs in fractures. The simulations also show that a dry fracture can serve as a very effective capillary and diffusion barrier for flow and transport between matrix blocks completely separated by the dry fracture. If matrix continuity across the dry fractures exits, the effectiveness of the barrier is reduced. In general, simulation results with dry fracture were considerably different from those not considering dry fractures, indicating that the effects of dry fractures on solute transport are important. For a typical degree $(10 \%)$ of matrix direct connection within dry fractures, we found that the transport of radionuclides (e.g., Tc) is significantly influenced by the existence of dry fractures and direct matrix-matrix connections, while the impact on the transport of environmental tracers with higher molecular diffusion is relatively insensitive. One important implication of this study is that dry-fracture effects need to be incorporated into modeling of radionuclide transport through the unsaturated zone of Yucca Mountain. 


\section{Acknowledgments}

The authors greatly appreciate the helpful discussions with Kazumasa Ito and Stefan Finsterle of Lawrence Berkeley National Laboratory (Berkeley Lab). The initial version of the manuscript was reviewed by Stefan Finsterle, Timothy Kneafsey, and Dan Hawkes at Berkeley Lab. This work was supported by the Director, Office of Civilian Radioactive Waste Management, U.S. Department of Energy, through Memorandum Purchase Order EA9013MC5X between Bechtel SAIC Company, LLC and the Berkeley Lab. The support is provided to Berkeley Lab through the U.S. Department of Energy Contract No. DE-AC03-76SF00098. 


\section{References}

Ahlers, C.F. and H.H. Liu, Calibrated Properties Model, MDL-NBS-HS-000003 REV 00, Analysis Modeling Report, Yucca Mountain Nuclear Waste Disposal Project, Lawrence Berkeley National Laboratory, Berkeley, CA, CRWMS M\&O, Las Vegas, NV, 2000

Birgersson, L., L. Moreno, I. Neretnieks, H. Widen, and T. Agren, A tracer migration experiment in a small fracture zone in granite, Water Resour. Res., 29, 12, 38673838,1993

Bodvarsson, G. S. and H. H. Liu, C. F. Ahlers, Y. S. Wu, and E. Sonnenthal, Parameterization and upscaling in modeling flow and transport at Yucca Mountain, in Conceptual models of flow and transport in fractured vadose zone, National Academy Press, Washington, DC, 2000

Bodvarsson, G. S., W. Boyle, R. Patterson, and D. Williams, Overview of scientific investigations at Yucca Mountain - the potential repository for high-level nuclear waste, J. Contam. Hydrol., 38, 3-24, 1999

Callahan, T.J., P. W. Reimus, R.S. Bowman, and M.J. Haga, Using multiple experimental methods to determine fracture/matrix interactions and dispersion of nonreactive solutes in saturated volcanic tuff, Water Resour. Res., 36, 12, 3547-3558, 2000

Flint, A. L., J. A. Hevesi, and L. E., Flint, Conceptual and numerical model of infiltration for the Yucca Mountain area, Nevada, U.S. Geological Survey Water Resources Investigation Report. U.S. Geological Survey, 1997

Glass, R. J., M. J. Nicholl, and V. C. Tidwel, Challenging and improving conceptual models for isothermal flow in unsaturated, fractured rocks through exploration of small-scale processes. Rep. SAND 95-1824, Sandia National Laboratories, Albuquerque, NM, 1996

Ho, C. K., Models of fracture-matrix interactions during multiphase heat and mass flow in unsaturated fractured porous media, in Sixth Symposium on Multiphase Transport in Porous Media, ASME International Mechanical Engineering Congress and Exposition, Am. Soc. of Mech. Eng., Dallas, TX, 1997

Liu, H.H., C. Doughty, and G. S. Bodvarsson, An active fracture model for unsaturated flow and transport in fractured rocks, Water Resour. Res., 34, 10, 2633-2646, 1998

Liu, H. H., C. B. Haukwa, F. Ahlers, G. S. Bodvarsson, A. L. Flint, and W. B. Guertal, Modeling flow and transport in unsaturated fractured rocks; an evaluation of the continuum approach, Report LBL-46571. Lawrence Berkeley National Laboratory, CA, 2001

Moench, A.F., Convergent radial dispersion in a double-porosity aquifer with fracture skin: Analytical solution and application to a field experiment in fractured chalk, Water Resour. Res., 31, 8, 1823-1835, 1995

Moridis, G. and Q. Hu, Radionuclide transport models under ambient conditions, MDLNBS-HS-000008 REV 00, Analysis Modeling Report, Yucca Mountain Nuclear Waste Disposal Project, Lawrence Berkeley National Laboratory, Berkeley, CA, CRWMS M\&O, Las Vegas, NV, 2000 
Mualem, Y., A new model for predicting the hydraulic conductivity of unsaturated porous media. Water Resour. Res., 12, 513-522, 1976

Nieder-Westermann, G. H. Fracture geometry analysis for the stratigraphic units of the repository host horizon, ANL-EBS-GE-000006 REV 00, Analysis Modeling Report, Yucca Mountain Nuclear Waste Disposal Project, Lawrence Berkeley National Laboratory, Berkeley, CA, CRWMS M\&O, Las Vegas, NV, 2000

Neretnieks, I., Diffusion in the rock matrix: An important factor in radionuclide retardation? J. Geophys. Res. 85, B8, 4379-4397, 1980

Novakowski, K.S., and P. A. Lapcevic, Field measurement of radial solute transport in fractured rock, Water Resour. Res., 30, 1, 27-44, 1994

Pruess, K., B. Faybishenko, and G.S. Bodvarsson, Alternative concepts and approaches for modeling flow and transport in thick unsaturated zones of fractured rocks, $J$. Contam. Hydro., 38, 1-3, 281-322, 1999

Pruess, K., A mechanistic model for water seepage through thick unsaturated zones in fractured rocks of low matrix permeability, Water Resour. Res., 35, 4, 1039-1051, 1997

Rasmussen, T. C., Steady fluid flow and travel times in partially structured fractures using a discrete air-water interface, Water Resour. Res., 27, 1, 67-76, 1991

Robinson, B. A., and G. Y. Bussod, Radionuclide transport in the unsaturated zone at Yucca Mountain: Numerical Model and preliminary field observations, in Dynamics of Fluids in Fractured Rock, Geophysical Monograph 122, 323-336, American Geophysical Union, Washington, DC, 2000

Shapiro, A.M., Effective matrix diffusion in kilometer-scale transport in fractured crystalline rock, Water Resour. Res., 37, 3, 507-522, 2001

van Genuchten, M. A Closed-Form Equation for Predicting the Hydraulic Conductivity of Unsaturated Soils, Soil Sci. Soc. Am. J., 44, 5, 892-898, 1980

Wang, J. S.Y, and T. N. Narashimhan, Unsaturated flow in fractured porous media, In Bear, J. C., C. F. Tsang, and G. de Marsily (eds.), Flow and Contaminant Transport in Fractured Rock, Academic Press, San Diego, CA, 1993

Wu, Y. S., C. F. Ahlers, P. Fraser, A. Simmons, K. Pruess, Software qualification of selected TOUGH2 modules. Report LBNL-39490. Lawrence Berkeley National Laboratory, Berkeley, CA, 1996 
Table 1. Input parameters for T2R3D simulations [Ahlers and Liu, 2000]

\begin{tabular}{lll}
\hline Material & Matrix & Fracture \\
\hline Porosity, $\phi$ & 0.11 & 1.00 \\
Residual Sat. $\mathrm{S}_{r}$ & 0.19 & 0.01 \\
Permeability, $\mathrm{k}\left(\mathrm{m}^{2}\right)$ & $4.07 \mathrm{E}-18$ & $1.70 \mathrm{E}-11$ \\
$\alpha^{*}\left(1 / \mathrm{P}_{\mathrm{a}}\right)$ & $3.86 \mathrm{E}-6$ & $5.16 \mathrm{E}-4$ \\
$\mathrm{~m}^{*}$ & 0.291 & 0.608 \\
\hline
\end{tabular}

* van Genuchten parameters, $\mathrm{m}=1-1 / \mathrm{n}$

Table 2. Maximum Peclet numbers calculated with maximum horizontal liquid velocity

\begin{tabular}{lc|ccc}
\hline $\begin{array}{l}\text { Direct matrix-matrix } \\
\text { Connection }\end{array}$ & ${ }^{*} V_{\mathrm{h}, \max }$ & $\mathrm{D}_{0}=3.20 \mathrm{E}-11$ & $\mathrm{D}_{0}=4.55 \mathrm{E}-10$ & $\mathrm{D}_{0}=2.00 \mathrm{E}-09$ \\
\hline No Connection & $1.57 \mathrm{E}-12$ & 0.0210 & 0.0015 & 0.0003 \\
$1 \%$ & $3.55 \mathrm{E}-12$ & 0.0475 & 0.0033 & 0.0008 \\
$10 \%$ & $4.58 \mathrm{E}-12$ & 0.0613 & 0.0043 & 0.0010 \\
$20 \%$ & $4.75 \mathrm{E}-12$ & 0.0636 & 0.0045 & 0.0010 \\
No Dry Fracture & $4.93 \mathrm{E}-12$ & 0.0660 & 0.0046 & 0.0011 \\
\hline
\end{tabular}

Maximum Peclet number $=V_{\mathrm{h}, \max } \cdot \mathrm{d} / \mathrm{D}_{\mathrm{e}}$, where $V_{\mathrm{h}, \max }=\operatorname{maximum}$ horizontal liquid velocity $(\mathrm{m} / \mathrm{s})$, the distance $(d)$ between the active fracture and first matrix is $0.2998 \mathrm{~m}$, and $D_{e}=\tau \cdot D_{0}$, where $\tau$ is tortuosity $(0.7)$. 


\section{List of Figures}

Figure 1. Schematics of a fracture network including active fractures and dry fractures

Figure 2. Dry fractures separating matrix blocks and asperity of matrix blocks

Figure 3. Schematics of a fracture-matrix system consisting of 15 matrix blocks

Figure 4. Breakthrough curves of solutes with various molecular diffusion coefficients $\left(\mathrm{m}^{2} / \mathrm{s}\right)$ migrating in fracture-matrix system with no dry fracture (a) and with dry fractures but no matrix-matrix direct connection (b). Tracer breakthroughs are represented by the ratio of bottom cumulative tracer flux $(\mathrm{kg})$ to the initial tracer mass $(\mathrm{kg})$ placed in the source.

Figure 5. Water saturation in the fracture-matrix system measured in the middle $(100 \mathrm{~m}$ depth) of the system at the steady state of water flow

Figure 6. Breakthrough curves of solutes with (a) lower molecular diffusion coefficient $\left(\mathrm{D}_{0}=3.2 \mathrm{E}-11 \mathrm{~m}^{2} / \mathrm{s}\right),(\mathrm{b})$ low molecular diffusion coefficient $\left(\mathrm{D}_{0}=4.55 \mathrm{E}-10 \mathrm{~m}^{2} / \mathrm{s}\right)$ and (c) high molecular diffusion $\left(\mathrm{D}_{0}=2.00 \mathrm{E}-09 \mathrm{~m}^{2} / \mathrm{s}\right)$ in the fracture-matrix system with various content of direct matrix-matrix connections. Tracer breakthroughs are represented by the ratio of bottom cumulative tracer flux $(\mathrm{kg})$ to the initial tracer mass $(\mathrm{kg})$ placed in the injection source.

Figure 7. Distribution of a tracer $(\mathrm{kg})$ with $\mathrm{D}_{0}=4.55 \mathrm{E}-10 \mathrm{~m}^{2} / \mathrm{s}$ at 3000 years after injection. (a) dry fractures without direct matrix-matrix connection, (b) dry fractures with $1 \%$ matrix-matrix connection, (c) dry fractures with $10 \%$ matrixmatrix connection, and (d) no dry fractures between two half fractures at the sides. 
Figure 1

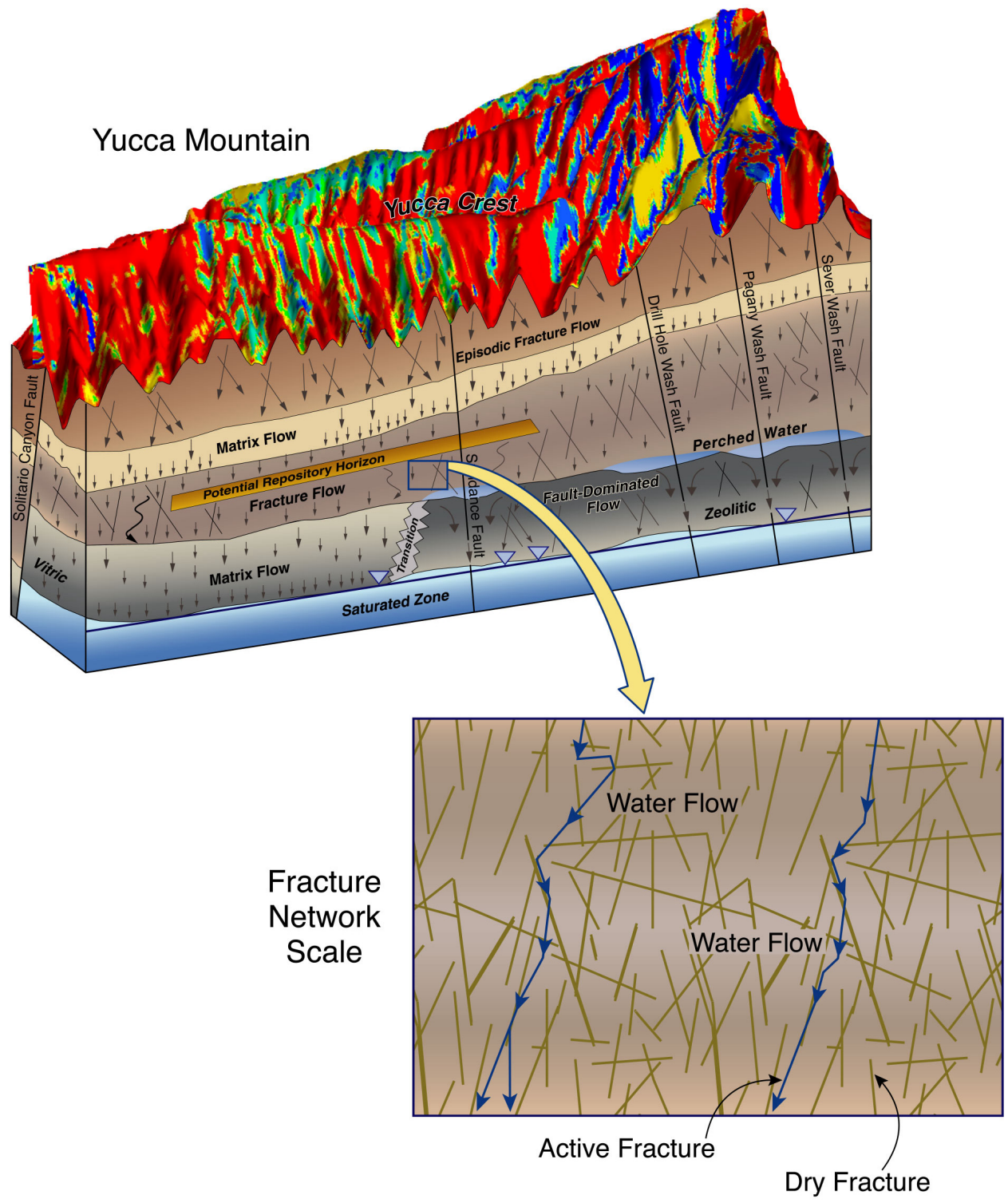

UZ02-003 
Figure 2

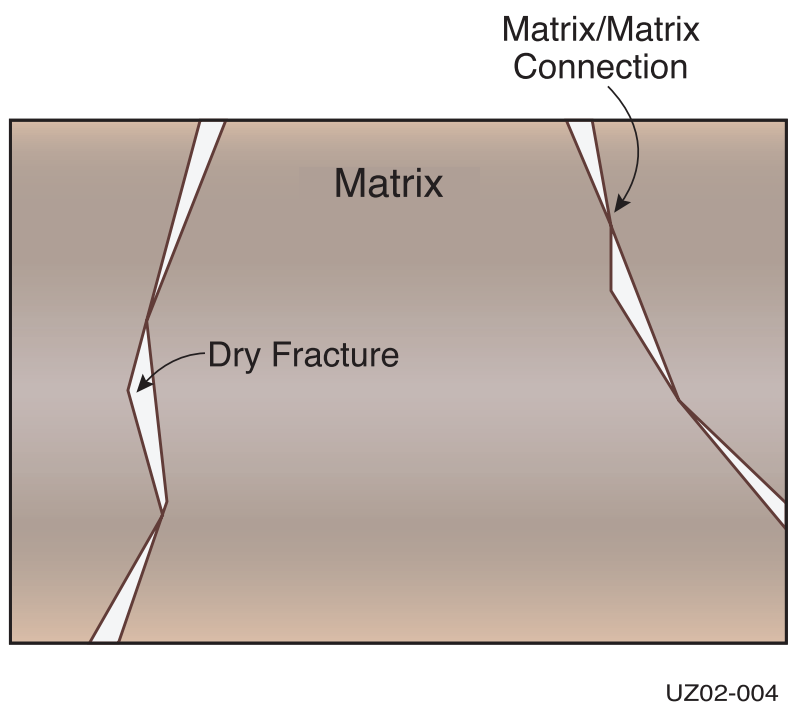


Figure 3

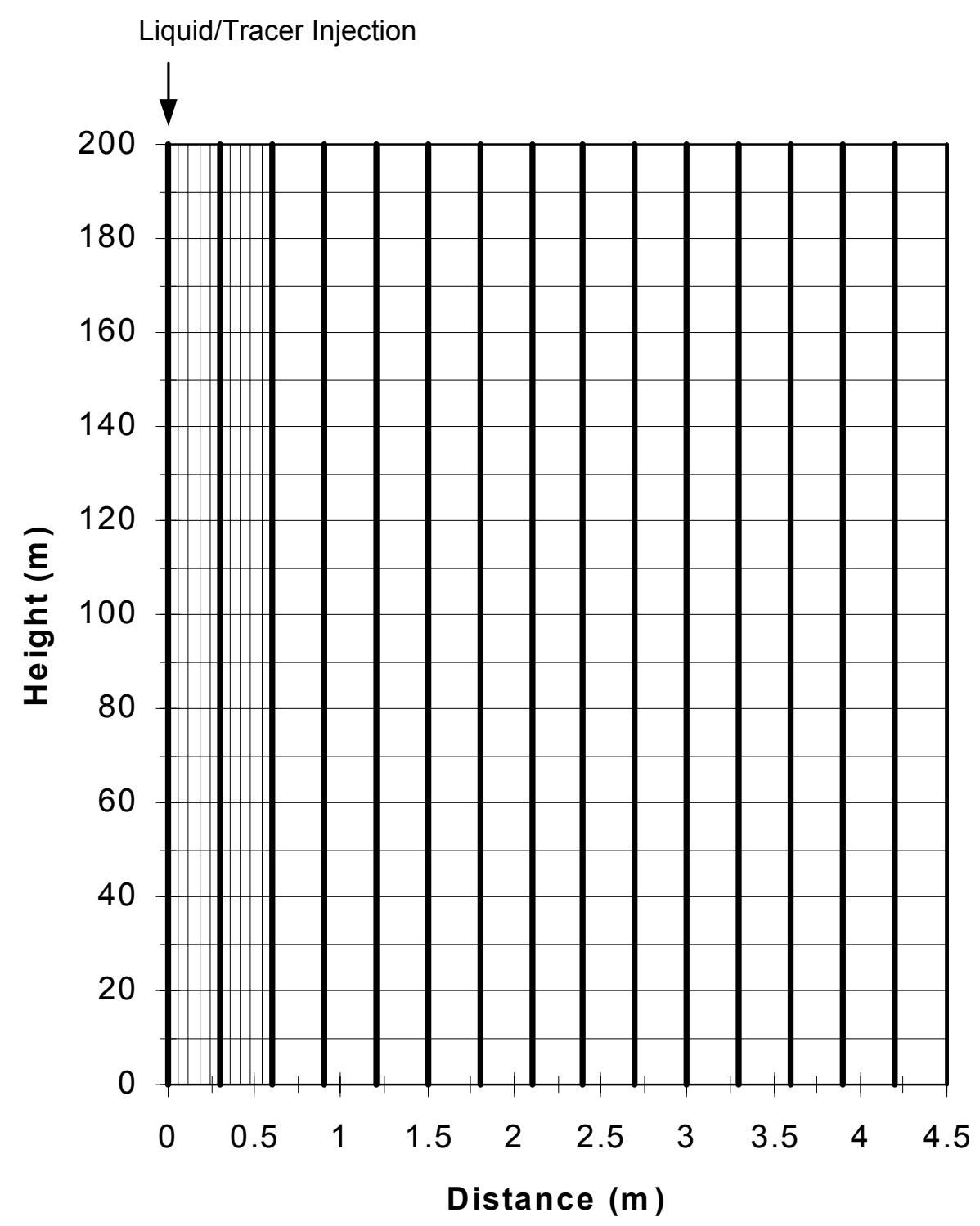


Figure 4
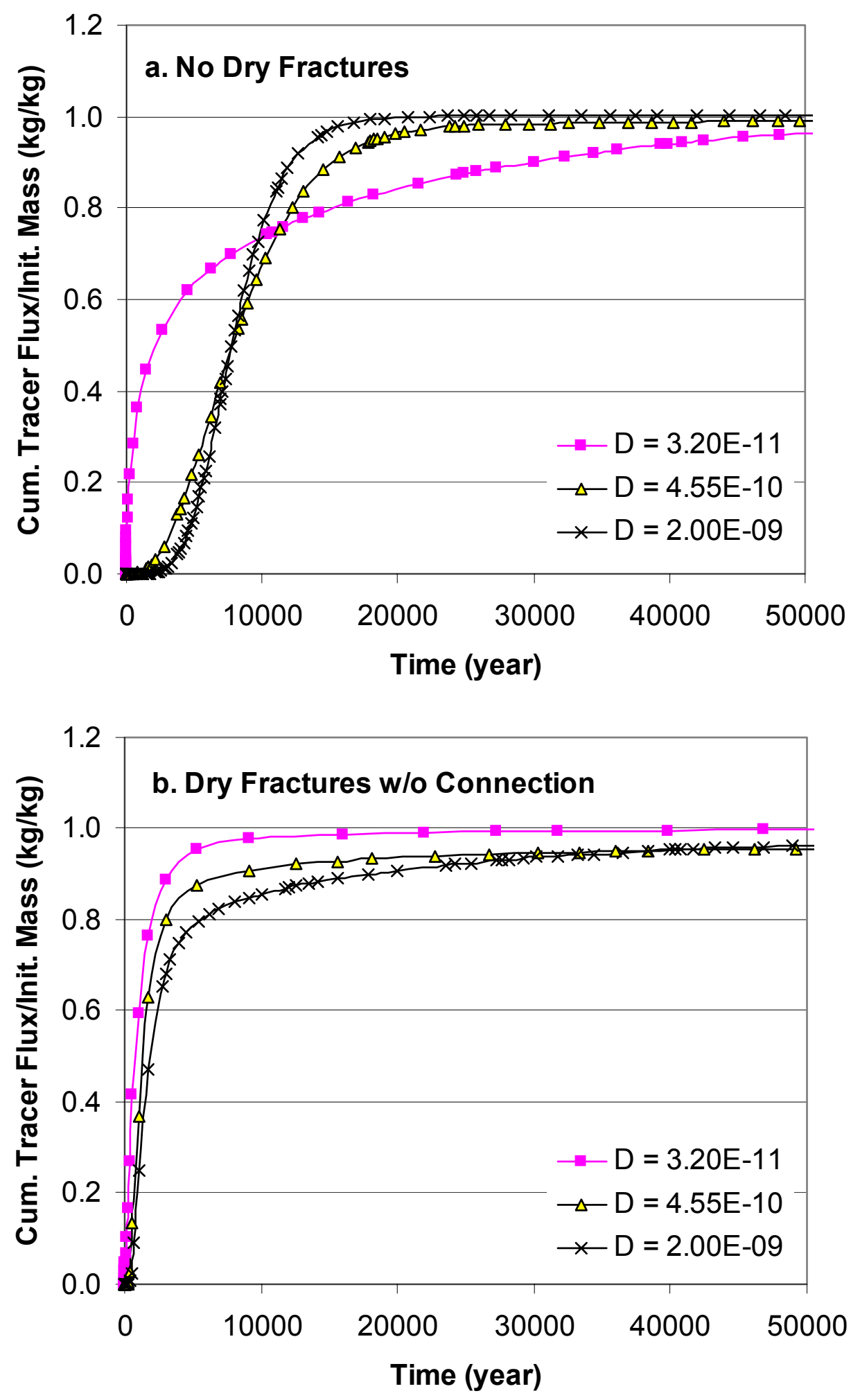
Figure 5

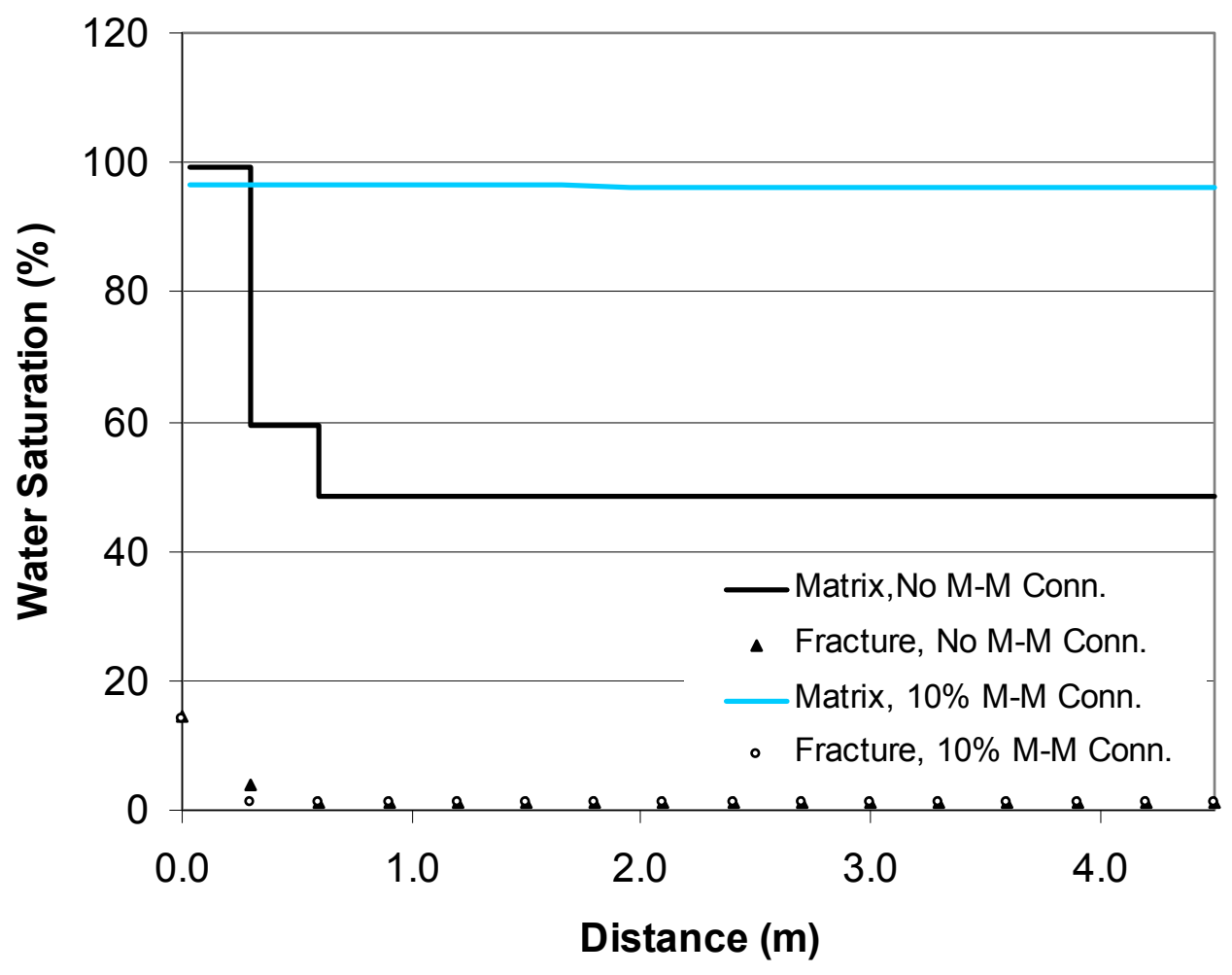


Figure 6.
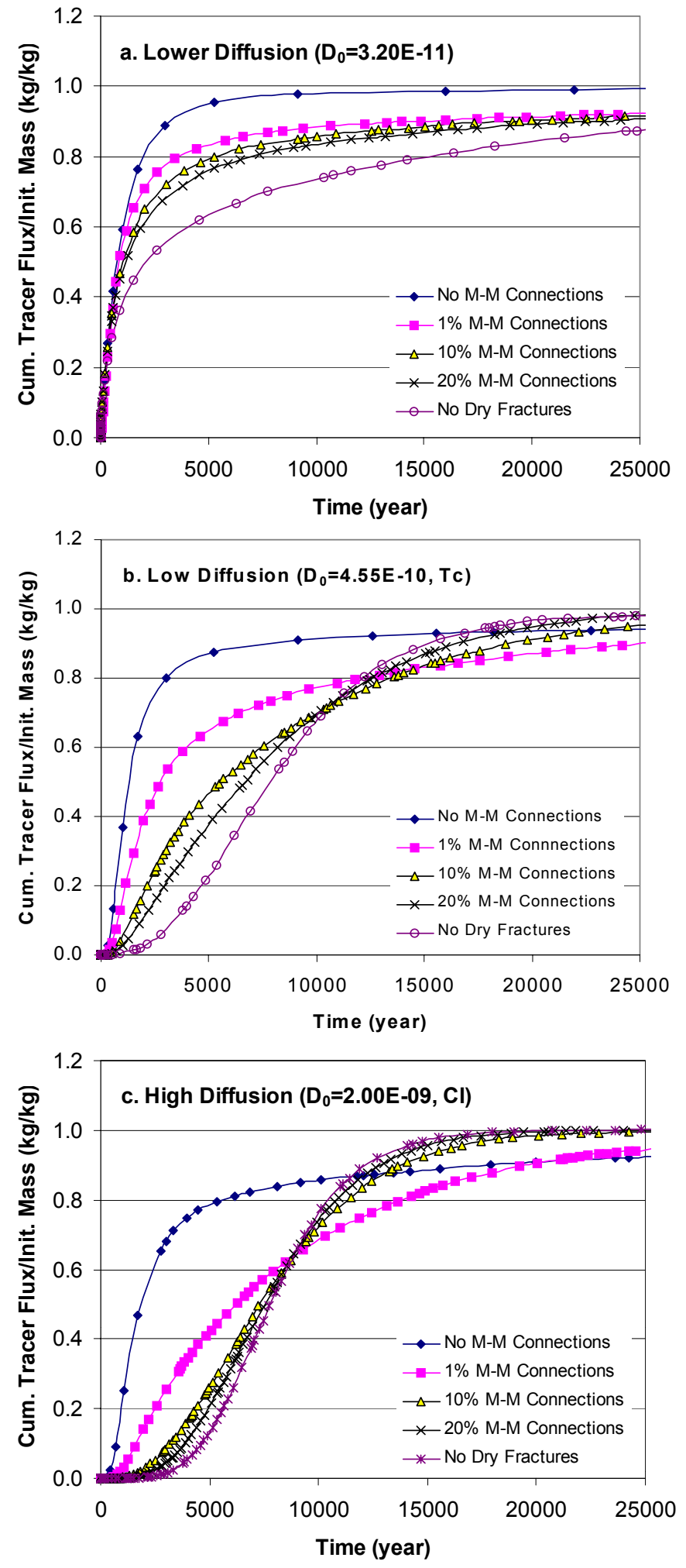
Figure 7.
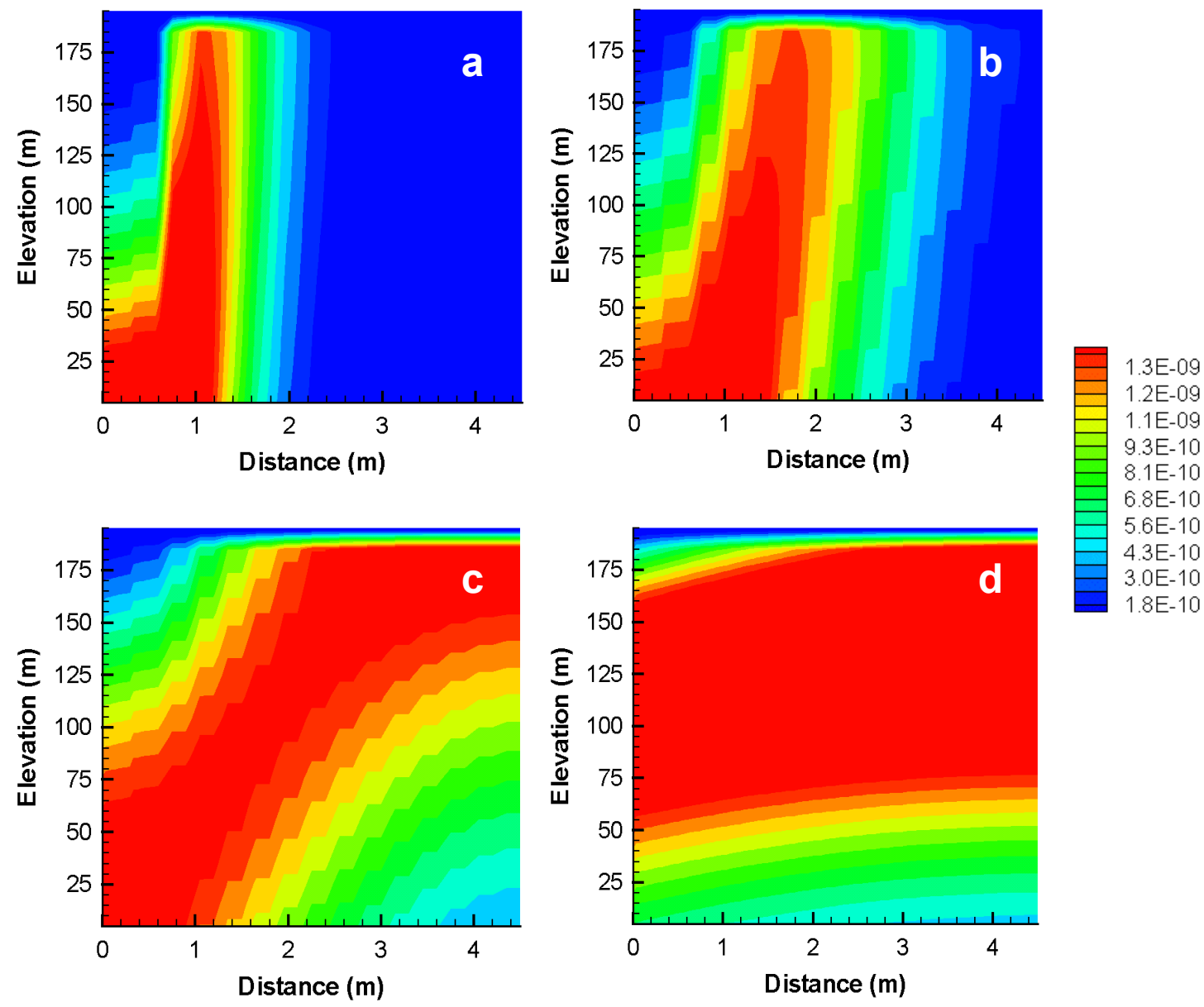